\title{
Insights Before Flights: How Community Perceptions Can Make or Break Medical Drone Deliveries
}

\author{
Susan Truog ${ }^{1, *}$, Luciana Maxim ${ }^{1}$, Charles Matemba ${ }^{2}$, Carla Blauvelt ${ }^{2}$, Hope Ngwira ${ }^{2}$, \\ Archimede Makaya ${ }^{3}$, Susana Moreira ${ }^{4}$, Emily Lawrence ${ }^{1}$, Gabriella Ailstock ${ }^{1}$, Andrea Weitz ${ }^{5}$, \\ Melissa West ${ }^{1}$ and Olivier Defawe ${ }^{1}$ \\ 1 VillageReach, 2900 Eastlake Avenue East, \#230, Seattle, WA 98102, USA; \\ luciana.maxim@villagereach.org (L.M.); emily.lawrence@villagereach.org (E.L.); \\ gabriella.ailstock@villagereach.org (G.A.); melissa.west@villagereach.org (M.W.); \\ olivier.defawe@villagereach.org (O.D.) \\ 2 VillageReach, P.O. Box 31348, Lilongwe 3, Malawi; charles.matemba@villagereach.org (C.M.); \\ carla.blauvelt@villagereach.org (C.B.); hope.ngwira@villagereach.org (H.N.) \\ 3 VillageReach, 8B, avenue Mongala, Suite 07, Kinshasa, Gombe, Democratic Republic of Congo; \\ archimede.makaya@villagereach.org \\ 4 VillageReach, Rua das Roasas, No. 105, Somerschield II, Maputo, Mozambique; \\ susana.moreira@villagereach.org \\ 5 Independent Researcher, Lubbock, TX 79424, USA; andrea.weitz@usc.edu \\ * Correspondence: susie.truog@villagereach.org
}

Received: 30 June 2020; Accepted: 27 August 2020; Published: 30 August 2020

\begin{abstract}
Drones are increasingly used to transport health products, but life-saving interventions can be stalled if local community concerns and preferences are not assessed and addressed. In order to inform the introduction of drones in new contexts, this paper analyzed similarities and differences in community perceptions of medical delivery drones in Malawi, Mozambique, the Democratic Republic of the Congo (DRC) and the Dominican Republic (DR). Community perceptions were assessed using focus group discussions (FGDs) and key informant interviews (KIIs) conducted with stakeholders at the national level, at health facilities and in communities. Data were collected on respondents' familiarity with drones, perceptions of benefits and risks of drones, advice on drone operations and recommendations on sharing information with the community. The comparative analysis found similar perceptions around the potential benefits of using drones, as well as important differences in the perceived risks of flying drones and culturally appropriate communication mechanisms based on the local context. Because community perceptions are heavily influenced by culture and local experiences, a similar assessment should be conducted before introducing drone activities in new areas and two-way feedback channels should be established once drone operations are established in an area. The extent to which a community understands and supports the use of drones to transport health products will ultimately play a critical role in the success or failure of the drone's ability to bring life-saving products to those who need them.
\end{abstract}

Keywords: medicines drone delivery; healthcare logistics; UAV for human health

\section{Introduction}

Medical delivery drones have the potential to resolve persistent transportation challenges, ensuring reliable access to medicines in areas not currently or consistently reached by ground transportation. Drones were first used for military surveillance and combat, leading to security and privacy concerns around their use [1]. In the past decade, the use of drones has expanded to commercial and civil purposes, including disaster management, photography and mapping. Increasingly, drones are being 
considered for delivery, including consumer goods, emergency supplies and health products, such as vaccines, blood products and laboratory samples [2-5]. Medical delivery by drone has gained momentum particularly in sub-Saharan Africa, with ongoing operations in Rwanda, Ghana and Malawi and small-scale projects moving forward in other countries [6-9]. There is limited published evidence around how the public perceives the increasing use of medical delivery drones, although there is some evidence that the public is most supportive when drones are used for social good, whether for medical delivery or other purposes [10]. This evidence has been generated primarily by academic institutions and non-governmental organizations, and few drone projects begin with comprehensive assessments of community perceptions or monitor how perceptions evolve over the course of a project. As with any new technology, misinformation and rumors about the use of drones can spread more quickly than truth [11], and in the case of medical delivery drones, can stall the adoption of an intervention that could save lives.

In the few published studies available, the public are generally accepting of the use of drones when they approve of the purpose of the flight and the actors involved [12,13], when they become more familiar with the potential benefits of drones [14], and when regulations protect civil liberties [15]. A 2017 study of community concerns about potential uses of drones illustrated that these preferences are context-specific. In Malawi, all community members interviewed supported the use of drones to deliver documents, while half of the community members interviewed in Zanzibar supported the same use [16]. A 2018 analysis in the United Kingdom found different preferences for the use of drones in each of five cities, with a common theme that drones are most acceptable when used for societal good [10]. A 2015 study of community perceptions of drones used to map flooding in Tanzania found that direct exposure to drones increased acceptance of their use; nearly nine out of 10 respondents became more accepting of drones after witnessing successful flights [17].

When the public is not familiar with drones, perceptions have been found to be neutral. However, a negative experience on first exposure to a new technology can sway public opinion, after which point, attitudes can be difficult to change $[14,18,19]$. In one case, United Nations (UN) peacekeepers in the Democratic Republic of the Congo (DRC) introduced drones to monitor rebel movements, but when a drone crashed and damaged farmland, mistrust of the peacekeepers and their mission grew in the community. The project had issued press releases and engaged local leaders before implementation, but left out the general public, who were dissatisfied with the response to the crash [20]. More recently, an American town had a similar experience when its police department announced plans to use drones to monitor social distancing and COVID-19 symptoms, without consulting the community. They were forced to cancel their plans when privacy concerns led to public outcry [21].

In order to avoid exacerbating underlying context-specific fears and halting progress towards reaching all people with life-saving products, it is important that governments, drone companies and other implementers understand context-specific concerns and preferences for the use of drones. This manuscript analyzes data from community perceptions assessments in four low-income countries to identify areas of general, overarching agreement as well as topics which necessitate investigation within the community before introducing the use of drones to transport health products in a new context.

\section{Materials and Methods}

Community perceptions were assessed in Malawi, Mozambique, DRC and the Dominican Republic (DR) as part of separate projects in each country. VillageReach, a non-governmental organization that aims to improve access to primary health care, works with governments and drone technology providers to explore the feasibility and acceptability of introducing drones for medical delivery [22]. In Malawi, Mozambique and the DRC, the implementation team worked with the drone technology provider to present their technical capabilities and safety mechanisms and submit all required documentation to national civil aviation authorities to receive permission to fly drones beyond the visual line of sight (BVLOS). In the DR, VillageReach provided technical assistance to the Center for Drone Innovations, who facilitated flight permissions and project implementation. At the time of project implementation, 
regulations specific to drones were available in Malawi, Mozambique and the DR and were drafted during project implementation in the DRC [23-26]. Globally, drone regulations continue to evolve. (The Global Drone Regulations Database compiles regulations across all countries, including the four assessed in this assessment. It is available online at: https://droneregulations.info/index.html).

Although project implementation varied slightly within each of the four countries, Figure 1 illustrates the general timeline. Community perceptions assessments were conducted before the development and implementation of community outreach, followed by a series of drone test flights. In all four countries, the drones tested were fixed-wing, capable of vertical take-off and landing and battery-powered. Each drone could carry 2-3 kilograms of payload in a temperature-controlled compartment. Drone test flights were planned for a period of one week to one month, depending on the country, and traveled a distance of between 10 and $40 \mathrm{~km}$.

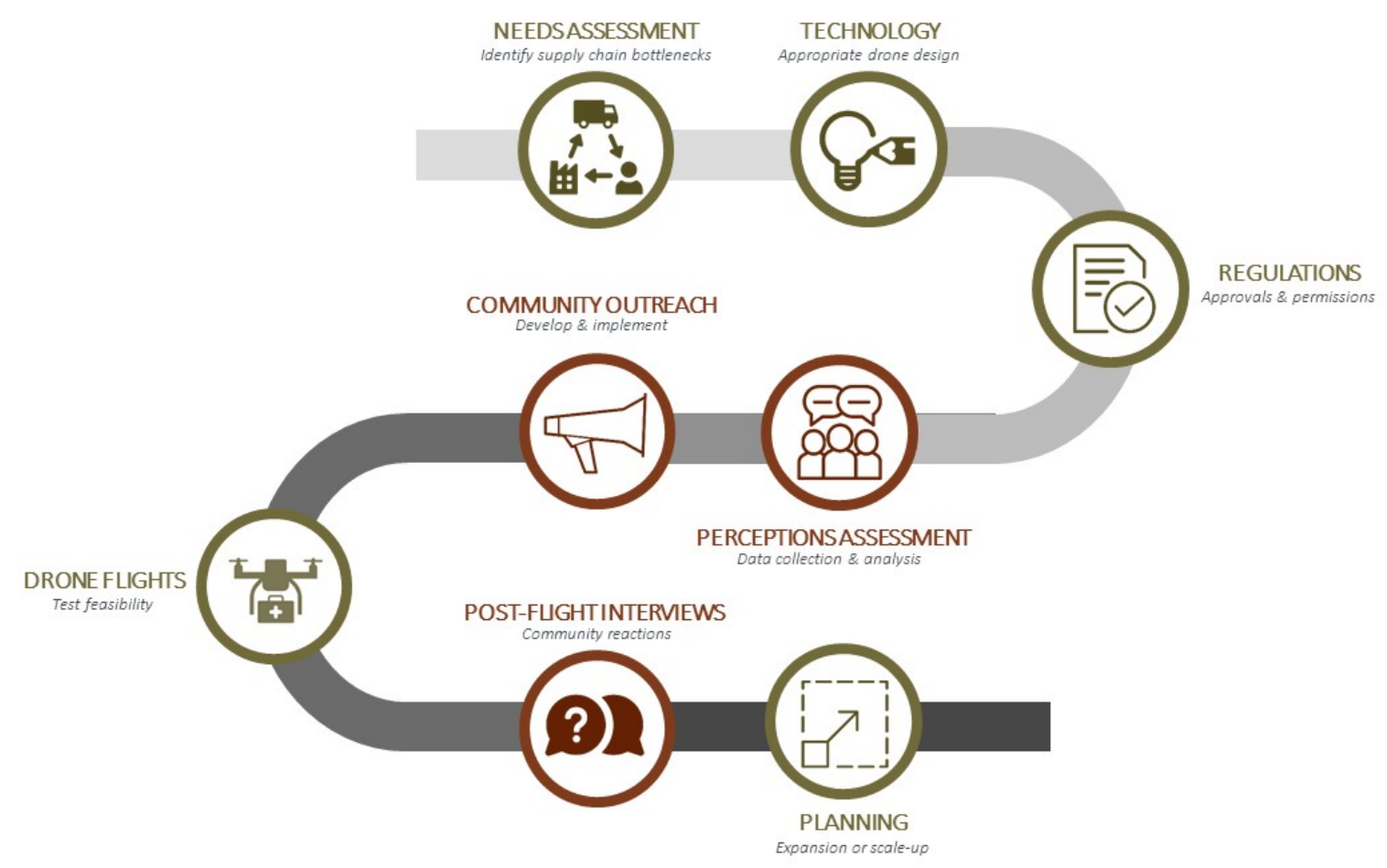

Figure 1. General drone feasibility testing project implementation plan.

VillageReach first assessed community perceptions of drones in Malawi in 2018, where the Malawi Ministry of Health and Population was planning to explore the use of drones to transport blood and oxytocin in maternal health emergencies from the Malawi Blood Transfusion Service center in urban Lilongwe to two health facilities, one in an urban area and one in a semirural area. The assessment used qualitative methods, including focus group discussions (FGDs) and key informant interviews (KIIs). (See the supplementary file for sample data collection tools and additional guidance to replicate the methods described here.) The assessment used a purposive sampling strategy to select FGD and KII participants within each country $[27,28]$. Participants included national and district level stakeholders, health workers, community leaders and the general public living near take-off and landing sites of planned drone test flights.

Respondents were asked a series of questions, organized in five categories: familiarity with drones, their perceptions of the benefits of using drones, their perceptions of the risks of using drones, advice on drone operations and recommendations on sharing information with the community. Respondents were asked about their familiarity with drones, then the intended use of drones was explained, and photographs were shown before asking respondents about potential benefits and risks of using drones for these purposes. 
In 2019, the community perceptions assessment methodology used in Malawi was adapted for drone projects in Mozambique, the DRC and the DR. Each project focused on medical drone delivery for a different purpose: in Mozambique, routine tuberculosis (TB) sputum sample transport; in the $\mathrm{DRC}$, routine immunization products; and in the DR, essential medicines. The assessment approach was adapted in each country to gather feedback around the use of drones for the specified purpose, and data collection tools and methods were adapted slightly based on the local implementation teams' preferences. For example, each assessment team worked with national and provincial stakeholders to select community leaders who were influential in their context. Additionally, in Mozambique and the DR, national and provincial level stakeholders did not participate in the perception assessments, and instead, were engaged directly for their buy-in and input throughout project implementation. Health workers and community leaders in Malawi participated in FGDs, while in the DR and DRC, they participated in KIIs due to logistical concerns, such as not leaving patients unattended. In Malawi and DRC, most health workers and community leaders were male, so FGDs with community members were held with more women than men.

Methods also varied slightly based on an area's prior experience with drones for medical delivery or other purposes. In Malawi, drones had been tested to transport health products in one of the landing sites, so results were analyzed with this in mind. In the DRC, a series of FGDs were also conducted after the drone test flights conducted as part of the 2019 project to determine whether observing the flights had an impact on perceptions. In the DR, drone test flights had been conducted in the same sites two years prior, so the tools were adapted to include questions about their reactions to those flights. Table 1 compares the assessment implementation in each of the four countries.

Table 1. Adaptation of community perceptions assessment methodology by country.

\begin{tabular}{ccccc}
\hline Comparison Point & Malawi & Mozambique & DRC & DR \\
\hline Date of data collection & Feb. 2018 & Mar.-May 2019 & Apr.-May 2019 & May 2019 \\
\hline Target product & Blood and oxytocin & $\begin{array}{c}\text { TB sputum } \\
\text { samples }\end{array}$ & $\begin{array}{c}\text { Immunization } \\
\text { products }\end{array}$ & $\begin{array}{c}\text { Essential } \\
\text { medicines }\end{array}$ \\
\hline $\begin{array}{c}\text { National-level } \\
\text { respondents }\end{array}$ & Yes & No & Yes & No \\
\hline $\begin{array}{c}\text { Population density } \\
\begin{array}{c}\text { Drone flights } \\
\text { completed before } \\
\text { assessment }\end{array}\end{array}$ Yrban \& semirural & $\begin{array}{c}\text { Peri-urban \& } \\
\text { semirural } \\
\text { site 2 years prior }\end{array}$ & Urban \& remote rural & $\begin{array}{c}\text { Peri-urban \& } \\
\text { semirural }\end{array}$ \\
\hline
\end{tabular}

Ethical approval was obtained in Malawi from the National Health Sciences Research Committee, as part of a larger research protocol on the costs and benefits of medical drone delivery. In Mozambique, the assessment methodology received ethical approval from the National Bioethics and Health Committee, and the Ministry of Public Health approved the assessment in the DRC. In the DR, ethical approval was not required as the assessment was considered part of routine project implementation. Interviews were conducted in local languages: in Malawi, Chichewa and English; in Mozambique, Changana and Portuguese; in the DRC, Lingala and French; and in the DR, Spanish. Informed consent was secured for all interviews. Personal identifying information was not retained for analysis, although job function of government officials, community leaders and health workers was recorded, and sex and location was recorded for all participants. Table 2 presents the breakdown of assessment respondents by level and by sex. 
Table 2. Number of focus group discussion (FGD) and key informant interview (KII) respondents by level and by sex.

\begin{tabular}{|c|c|c|c|c|c|}
\hline Country & $\begin{array}{c}\text { National \& } \\
\text { Provincial } \\
\text { Officials }\end{array}$ & $\begin{array}{l}\text { Health } \\
\text { Workers }\end{array}$ & $\begin{array}{l}\text { Community } \\
\text { Leaders }\end{array}$ & $\begin{array}{l}\text { Community } \\
\text { Members }\end{array}$ & Total \\
\hline \multirow[b]{2}{*}{ Malawi } & 35 men & 21 men & 22 men & 0 men & 78 men \\
\hline & $\begin{array}{l}11 \text { women } \\
\text { (4 FGD) }\end{array}$ & $\begin{array}{l}12 \text { women } \\
\text { (2 FGD) }\end{array}$ & $\begin{array}{l}10 \text { women } \\
\text { (2 FGD) }\end{array}$ & $\begin{array}{l}19 \text { women } \\
\text { (2 FGD) }\end{array}$ & $\begin{array}{l}52 \text { women } \\
(10 \text { FGD) }\end{array}$ \\
\hline \multirow{3}{*}{ Moz. } & - & $1 \mathrm{man}$ & 14 men & 33 men & 48 men \\
\hline & - & 18 women & 5 women & 33 women & 56 women \\
\hline & - & (19 KII) & (2 FGD) & (8 FGD) & (19 KII, 10 FGD) \\
\hline \multirow{3}{*}{ DRC } & 31 men & 14 men & 10 men & 14 men & 69 men \\
\hline & 6 women & 6 women & - & 34 women & 46 women \\
\hline & (2 FGD) & (10 KII, 1 FGD) & (1 FGD) & (6 FGD) & (10 KII, 10 FGD) \\
\hline \multirow{3}{*}{ DR } & - & 6 men & 3 men & 39 men & 48 men \\
\hline & - & 12 women & - & 41 women & 53 women \\
\hline & - & $(18 \mathrm{KII})$ & (3 KII) & (10 FGD) & (21 KII, 10 FGD) \\
\hline \multirow{4}{*}{ Total } & 66 men & 42 men & 49 men & 86 men & 241 men \\
\hline & 17 women & 48 women & 15 women & 127 women & 209 women \\
\hline & (6 FGD) & (47 KII, 3 FGD) & (3 KII, 5 FGD) & (26 FGD) & (50 KII, 41 FGD) \\
\hline & 83 participants & 90 respondents & 64 respondents & 213 respondents & 450 respondents \\
\hline
\end{tabular}

FGD and KII data were analyzed under each of the five question categories using inductive content analysis, which breaks qualitative data into small units of content, describes them and quantifies the frequency with which themes appear $[29,30]$. The results were used within each country to tailor a community outreach strategy to accompany the drone test flights to ensure that the general public was aware of the purpose and scope of the drone flights and safety precautions to take in case of an adverse event. See the supplementary file for a community outreach strategy template. For this paper, the results were compared across the four countries to identify areas of similarity and difference to inform the introduction of drones to transport health products in the future. The supplementary file contains a summary of the data collected.

\section{Results}

\subsection{Familiarity with Drones}

Across all four countries, awareness of drones varied by level and between urban and rural sites. Where they were interviewed (in Malawi and in the DRC), higher-level government stakeholders were much more familiar with drones than the general public. In the 4 FGDs conducted with national and district stakeholders in Malawi, all respondents were aware of drones, whereas in the four FGDs conducted with general community members in Malawi, few respondents were aware of drones for any purpose. Health workers were also more likely than the general public to be aware of drones, with 15 of 19 health workers participating in KIIs in Mozambique reporting familiarity and only a minority of participants in 10 FGDs with community leaders and general community members aware of drones. These differences may be because some respondents had a basic orientation to the drone project. Additionally, because government stakeholders and health workers primarily lived or worked in urban or semi-urban capital cities, they were more likely to have been exposed to media portrayals of drones. Community-level respondents in three FGDs in the semi-urban area assessed in the DRC were more likely to be aware of drones than those participating in the three FGDs in the rural area assessed in the DRC. However, across respondents at all levels in all four countries, only those who had direct exposure to the project were aware of the use of drones to transport health products. Almost all of those who were familiar with drones associated them with photography or surveillance. 


\subsection{Perceptions of Benefits of Using Drones}

Once oriented to medical delivery drones, respondents were largely supportive of their use and identified numerous benefits. The most frequently cited benefit was faster transport time (all 10 FGDs in Malawi, 22 of 29 KIIs and FGDs in Mozambique, 11 of 16 KIIs and FGDs in the DRC and 17 of 31 KIIs and FGDs in the DR). Respondents also cited increased access to products and services in hard-to-reach areas, saving patients time and money by bringing products or services closer to where they live and ensuring the quality of items transported. Overall, participants agreed that drone transport could ensure access to life-saving products, as evidenced in the quotes below.

We need [drones]. Often our [tuberculosis test] results are lost at the hospital, when transported by cars or motorbikes ... [We] believe things will be made easier, so we can get the results as fast as we can. (Mozambique)

Drones can get to places that motor vehicles cannot reach. During rainy seasons, some roads and bridges get damaged. Drones will solve accessibility challenges in these situations. (Malawi)

Even though drones may be expensive, how much is this woman's life worth, my life, or my son's life? (Dominican Republic)

Some benefits were specific to the local context. A health worker participating in a KII and a community participant in an FGD in Mozambique thought that battery-operated drones may reduce reliance on fuel, an expense which can delay ground transport when the transporter relies on the government to disburse funds. In the DRC, where ground transport between the provincial warehouse and health facilities takes multiple days and required multiple forms of transport, which may be unsafe or unreliable, health workers also felt that drones would reduce the risk of product damage or transporter safety during transport to these remote areas. Furthermore, in DRC, health workers and community members expressed hopes that drones could be used in a wide variety of ways, including to carry food items, clothes, seeds for farmers, as well as letters and event invitations, salaries and election results to their remote community, resolving a critical accessibility issue for them. Some suggestions were overly optimistic about what the drones could carry, for example, transport of people in emergencies or transport of large items like mosquito nets and beds.

\subsection{Perceptions of Risks of Using Drones}

Respondents also agreed that drones may pose certain risks, although there were important differences in the risks identified based on the local context. Across all four countries, the most commonly perceived risk or concern was that drones may crash, may not arrive at their destination or may be otherwise unreliable. This concern was expressed in the majority of all FGDs and KIIs in all countries. Respondents felt that a crash could cause harm to people, crops or other property or to the products transported, and that crashes could be caused by wind, darkness, heavy rain or an operator with insufficient training.

We will think, 'What if it falls? What if it does not come? Did they put the [tuberculosis] samples in there and put my name correctly?' (Mozambique)

Most people had never seen technology that could be remotely piloted. In Malawi, community leaders expressed concern that the novelty of the drones could distract from daily activities, such as children at schools or drivers on the road. In addition, many respondents in Malawi identified a risk that drones could be associated with the supernatural. Specifically, health workers, community leaders and general community members in multiple FGDs and KIIs expressed concerns that if drones were used to transport blood, they may be perceived to be associated with "blood suckers" or recent attacks on people with albinism, as described below. 
You know that persons with albinism have been under attack in this country. Some have been killed. These people are afraid. Aircrafts flying over their houses scare them. I am thinking drones will not be different. (Malawi)

Superstitions were mentioned less frequently in other contexts, but in the DRC, community leaders in one site also felt that the public may think that autonomous aircraft may be possessed (diaboliques in French). Some health workers in Malawi were also concerned that patients may not think that the medicine transported by drone was real.

Government officials and health workers in multiple countries were also concerned about cost. In the DR, a health worker expressed concern that drones may not be a cost-effective solution compared to other public health initiatives that could impact the health and well-being of the community, and in Malawi, national level stakeholders expressed concern about the cost of buying and maintaining drones. In Mozambique and the DRC, some health workers expressed concern that drones may displace existing human resources involved in distributing medicines and other health products.

\subsection{Advice on Drone Operations}

Respondents were asked for their advice on who should operate drones and when and where drones should be operated. The results illustrated context-specific considerations for introducing drones. In the DR, respondents felt that drone operators should be trained and come from a trusted organization, and from the community where the drone will be used. They also thought that drone operations staff should be identified from outside the health center, as health center staff have high turnover. Community members in the DR also had advice about where drones should not be flown. The border between the DR and Haiti, known drug trafficking areas, and areas near the national park should be avoided so that drone activity is not confused with illicit activity. In Malawi, respondents recommended not flying near a refugee camp where perceptions of drones were not yet understood, and due to the diversity of cultural backgrounds and traumatic experiences, the drones would risk causing fear.

There were also concerns about the timing of drone flights. Health workers in Mozambique advised that drones should not be flown on weekends or during peak hours at the health center in order to minimize the burden on health workers' time. Both health workers and community members in Mozambique and Malawi felt that drones should not fly at night or during heavy rain to reduce the risk of a crash. In Malawi and the DRC, there was concern about flying drones on Sundays during church-going hours. However, participants in half of the FGDs with community members in Mozambique felt that drones should be available at all times and on all days to ensure reliable health care, as illustrated by this quote:

\section{Diseases do not have Saturday or Sunday. If there is someone who can fly them, they can fly every day.} (Mozambique)

\subsection{Recommendations on Sharing Information with the Community}

In each context, respondents were asked to identify any priority groups to directly reach out to with educational information about drones. Respondents in all four countries agreed that multiple methods are needed to reach a diverse group of community members, including the elderly, children, community leaders, and anyone living near a take-off or landing site or accessing services from the health facility. Community leaders, such as traditional or religious leaders, are seen across countries as critical communication channels, in addition to radio, television and other media. Each country also identified context-specific communication channels such as local health education promotion teams, teachers, administrative authorities or public announcement focal points. In the DRC, an indigenous population who may be more likely to associate the drones with superstitions were among those targeted with educational information. 


\subsection{Reactions to Drone Test Flights}

After drone test flights in the DRC, men and women who had observed the flights reported that they had first learned about the flights from multiple dissemination channels: radio announcements, health workers, community leaders, health promoters and word-of-mouth from other community members. A minority of respondents had not heard about the flights in advance, but upon observing the event, stayed to watch once they saw or heard the drones. Overall, respondents were excited to see the drone in their community.

[Drones are] a good thing. [There is] another atmosphere in the village. We have left everything to come see the drone. (DRC)

A few respondents reported that they were worried that the drones would not fly successfully or would not be able to carry the payload. After observing the flights, all respondents recommended that the government continue to transport health products by drone.

\section{Discussion}

\subsection{Tailored Community Outreach Strategies}

Overall, respondents held optimistic attitudes about the potential of drones to help address logistics challenges related to health products, particularly in their ability to reduce transport time. The risk of the drone crashing was a concern in all contexts. However, important differences were present in the additional specific benefits and risks perceived, advice on how to share information with the community and advice on how to start drone operations. Assessment results indicated an opportunity to rapidly build public support for medical drone deliveries by emphasizing potential context-specific benefits, directly addressing any local misconceptions and mitigating risks resulting from local experiences with drones.

As such, assessment results were used to tailor a community outreach strategy to provide educational information directly to the community in each context. For example, in Malawi, outreach targeted more people and included more time for open discussion in the semirural area than in the urban area due to the lack of familiarity with drones in the semirural area. In DRC, more detail was shared about the size and weight of the payload the drones could carry to ensure realistic expectations. In Mozambique, several health workers had heard that drones were used for photography, so it was important to communicate clearly that the project's drones would not be used for photography and that the community need not be concerned about privacy. Importantly, the community outreach also directly addressed all risks and misconceptions specific to the community. This input was critical to ensuring that communities were adequately informed about the potential benefits and risks of introducing drones and that the introduction of drones to transport health products was accepted by the community. Table 3 summarizes the adaptations made.

The development and implementation of a localized community outreach campaign in advance of operating drones for the first time is particularly important in case of an adverse event, as occurred in Malawi when a drone crashed in a field due to radio interference. Because the community was aware of the test flights and were informed of both the potential benefits and risks of drones, communities remained supportive of the use of drones despite this adverse event. Community leaders even invited the project to return for a second round of test flights after the crash as they highly valued projects that could help reduce the high maternal mortality rates in their area.

Comprehensively addressing community concerns and clearly communicating realistic benefits and risks yielded positive results in the DRC as well. Following successful drone test flights in 2019, national and provincial stakeholders recommended establishing a routine drone delivery system, including updating the community outreach strategy to expand to new sites within the targeted province. 
Table 3. Example adaptations as a result of community perceptions findings.

\begin{tabular}{|c|c|c|c|}
\hline Assessment Area & Country & Finding & Example Adaptation \\
\hline \multirow{2}{*}{$\begin{array}{l}\text { 1. Familiarity } \\
\text { with drones }\end{array}$} & Malawi & $\begin{array}{l}\text { Lower awareness in rural area } \\
\text { than urban area }\end{array}$ & $\begin{array}{c}\text { Community outreach conducted for } \\
3 \text { days in rural area compared to } \\
2 \text { days in urban area }\end{array}$ \\
\hline & Mozambique & $\begin{array}{c}\text { Many health workers are } \\
\text { familiar with drones for } \\
\text { photography }\end{array}$ & $\begin{array}{l}\text { Messages included that drones } \\
\text { would not be used for photography }\end{array}$ \\
\hline $\begin{array}{l}\text { 2. Perceived } \\
\text { benefits of drones }\end{array}$ & DRC & $\begin{array}{l}\text { Community members } \\
\text { believed that drones may } \\
\text { solve all problems, including } \\
\text { food delivery and salary } \\
\text { disbursement }\end{array}$ & $\begin{array}{l}\text { Messages shared carrying capacity } \\
\text { size and volume of drone and gave } \\
\text { concrete examples of } \\
\text { potential payloads }\end{array}$ \\
\hline \multirow{3}{*}{$\begin{array}{l}\text { 3. Perceived risks } \\
\text { of drones }\end{array}$} & All & $\begin{array}{l}\text { Drones may crash and cause } \\
\text { property or payload damage }\end{array}$ & $\begin{array}{l}\text { Project worked directly with civil } \\
\text { aviation to ensure adherence to all } \\
\text { regulations; developed and } \\
\text { communicated widely adverse } \\
\text { event procedures }\end{array}$ \\
\hline & Malawi & $\begin{array}{l}\text { Potential link to “blood } \\
\text { suckers," attacks against } \\
\text { persons with albinism and } \\
\text { other misconceptions }\end{array}$ & $\begin{array}{l}\text { Community outreach directly } \\
\text { addressed each misconception using } \\
\text { locally relevant means of } \\
\text { communication }\end{array}$ \\
\hline & DRC & $\begin{array}{l}\text { Medical delivery drones could } \\
\text { displace existing public sector } \\
\text { human resources }\end{array}$ & $\begin{array}{c}\text { Community outreach emphasizes } \\
\text { complementary role of drones and } \\
\text { that drones are used to access } \\
\text { unreachable sites }\end{array}$ \\
\hline \multirow[b]{2}{*}{$\begin{array}{l}\text { 4. Advice on } \\
\text { drone operations }\end{array}$} & Mozambique & $\begin{array}{l}\text { Avoid flying drones when the } \\
\text { receiving health facility is } \\
\text { overburdened, such as during } \\
\text { immunization sessions }\end{array}$ & $\begin{array}{l}\text { Establish a system in which the } \\
\text { receiving health facility determines } \\
\text { the arrival time of drones }\end{array}$ \\
\hline & DR & $\begin{array}{l}\text { Operator from a trusted } \\
\text { organization or local } \\
\text { community; not only health } \\
\text { center staff due to turnover }\end{array}$ & $\begin{array}{l}\text { Engage trusted organization or local } \\
\text { community representative in drone } \\
\text { demonstration flights and if drone } \\
\text { operations are introduced in the } \\
\text { longer-term, identify operators from } \\
\text { local area }\end{array}$ \\
\hline $\begin{array}{l}5 . \\
\text { Recommendations } \\
\text { on sharing } \\
\text { information }\end{array}$ & DRC & $\begin{array}{l}\text { Local community members } \\
\text { designated with the } \\
\text { responsibility of disseminating } \\
\text { announcements (crieurs in } \\
\text { French) were identified }\end{array}$ & $\begin{array}{l}\text { Crieurs were trained and mobilized } \\
\text { to go door-to-door and to gathering } \\
\text { places, such as markets to share key } \\
\text { messages about drones. }\end{array}$ \\
\hline
\end{tabular}

\subsection{Recommendations for Replication}

Because community perceptions are heavily influenced by culture and prior experience, the results from each country reflect the local beliefs, practices and attitudes of that area and should not be considered generalizable within or across countries. Governments, drone companies, and implementing partners should assess community perceptions of drones when proposing activities in a new area where attitudes and preferences are not well understood. In some cases, this may mean when moving into a new province within the same country if the cultural and social practices or experiences differ significantly. In collaboration with local stakeholders, new drone projects can adapt the qualitative data collection tools and methods used in this assessment to their intended use case and context. Purposive sampling at each level is sufficient at this phase of drone operations; rigorous statistical sampling is not required for such a descriptive assessment. 
Data should be collected by teams familiar with the local customs and who speak the local language. Project implementation teams can initiate the project with stakeholders at the national level, who can identify the assessment site and then provide the necessary permission to engage with the provincial level according to local protocol, who can then provide the necessary permission and guidance for community engagement. If the project implementation team is not from the local area, they could consider working through existing local structures or hiring a local community-based organization to assist with data collection in the community. Such a team would understand the local health system and know who to engage to select community respondents and organize interviews. The data collection team should provide opportunities to demystify drones by showing photographs of drone models and explaining their purpose in non-technical language, as well as videos of drone flights, if possible.

Assessment results should be analyzed for each of the five data categories (familiarity with drones, perceptions of benefits of drones, perceptions of risks of drones, advice on drone operations and recommendations on sharing information), comparing results across levels and location of respondent. A document should be created to summarize key messages and develop strategies for the community outreach campaign. To develop key outreach messages, key themes from the analysis should be addressed: benefits identified should be confirmed or clarified to temper expectations, risks should be explained, mitigation strategies developed and shared, and all advice and recommendations should be considered in project implementation planning.

Once key messages have been developed, they should be validated with national, provincial and community leaders. Implementation teams should consider mobilizing local health promotion teams who are already seen by the community as authoritative and trusted. Community outreach teams should be trained on the key messages and encouraged to identify context-specific methods of community outreach, leveraging multiple methods to reach a diverse population in the weeks leading up to the first drone flights in the area. During direct outreach activities, mobilizers should allow sufficient time for feedback and questions from the community to promote continued sharing and engagement.

As drone operations are further established in a community over a longer period of time, stakeholder and community satisfaction with the use of drones to transport health products should also be monitored and evaluated. Any concerns or issues that arise should be addressed in a timely manner through communication channels identified through the assessment. Drone projects should allocate sufficient time and budget to allow the implementation of the startup assessment as well as ongoing monitoring; this budget does not need to be extensive, as data collection can be combined with site scoping visits and should leverage existing personnel within the community.

The qualitative assessment described in this paper can be used to design quantitative survey methods which can be included as one component of larger-scale process and impact evaluations of drone operations, including not only community satisfaction with drone operations, but also supply chain impact, health impact and cost-effectiveness. Figure 2 lists potential research questions for the perception assessments and an evaluation of community satisfaction with ongoing drone operations.

While the perceptions assessment is intended to inform a tailored community outreach strategy and project implementation plan, once drones have been introduced to a community, their satisfaction should be evaluated in a more rigorous and reliable way using quantitative and qualitative methods. Where budget and time allows, a statistically significant sample can be taken to reliably evaluate the impact drone operations have on the community [31]. The perceptions assessment results in the identification of themes emerging from qualitative data, while a satisfaction evaluation is able to quantify community satisfaction with the benefits realized through drone operations. 


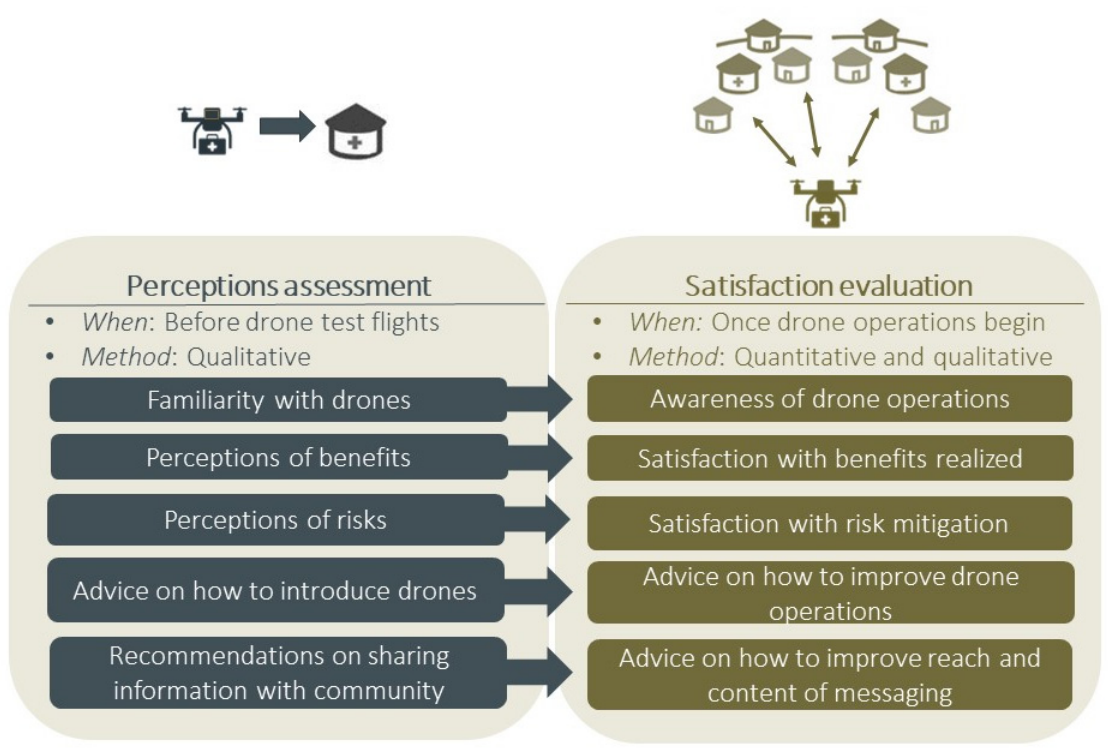

Figure 2. Research questions for perceptions assessment compared to satisfaction evaluation.

\section{Conclusions}

Stakeholder and community perceptions in four different countries revealed key areas of agreement, as well as context-specific differences that require a localized response. Governments, drone companies, and implementing partners are highly encouraged to initiate new drone activities with an assessment of the local community's perceptions to develop a comprehensive and tailored outreach strategy, whether drone operations will transport health products or have another purpose. As drone operations progress, ongoing monitoring and communication between the project implementation team and the community will promote the sustainability and success of medical drone delivery.

Supplementary Materials: The following are available online at http://www.mdpi.com/2504-446X/4/3/51/s1.

Author Contributions: Conceptualization, S.T., G.A., M.W. and O.D.; data curation, S.T.; formal analysis, S.T., L.M., C.M., and E.L.; funding acquisition, O.D.; methodology, S.T., L.M., C.M., C.B., A.M., S.M., and E.L.; writing-original draft, S.T. and A.W.; writing—review \& editing, S.T., L.M., C.M., C.B., H.N., A.M., S.M., E.L., G.A., A.W., M.W. and O.D. All authors have read and agreed to the published version of the manuscript.

Funding: Project implementation was funded by Grand Challenges Canada and Silicon Valley Community Foundation in Malawi; by Gavi, the Vaccine Alliance in DRC; the UK Department for International Development (DFID), initially through Frontier Technology Livestreaming, in Mozambique; and the Inter-American Development Bank (IDB) in the Dominican Republic. This comparative research was funded by the Bill \& Melinda Gates Foundation.

Acknowledgments: We acknowledge the contributions to the design and implementation of the assessment of Fannie Kachale and James Kandulu of the Ministry of Health and Population in Malawi and of Thokozani Chimenya of VillageReach; Dieudonne Nsekela and Freddy Nkosi of VillageReach and Theodore Assani of the Ministry of Public Health in the DRC; Barbara Jones Singer, Carla Lutucuta, Adam Wohlman, Alvo Ofumane and Ruth Bechtel of VillageReach, Manuel Raivoso of the Ministry of Health and Aderito Machava of Eduardo Mondlane University in Mozambique; and Orlando Richiez Perez of Centro de Innovacion de Drones in the DR. We also thank Erin Larsen-Cooper and Jessica Crawford of VillageReach for their support in review of this paper.

Conflicts of Interest: The authors declare no conflict of interest.

\section{References}

1. Sandvik, K. African Drones Stories. Behemoth J. Civiliz. 2015, 8, 73-96.

2. Konert, A.; Smereka, J.; Szarpak, L. The Use of Drones in Emergency Medicine: Practical and Legal Aspects. Emerg. Med. Int. 2019, 2019, 1-5. [CrossRef] [PubMed]

3. Balasingam, M. Drones in medicine-The rise of the machines. Int. J. Clin. Pract. 2017, 71, e12989. [CrossRef] [PubMed] 
4. Rosser, J.C.; Vignesh, V.; Terwilliger, B.A.; Parker, B.C. Surgical and Medical Applications of Drones: A Comprehensive Review. JSLS J. Soc. Laparoendosc. Surg. 2018, 22, 1-9. [CrossRef] [PubMed]

5. Thiels, C.A.; Aho, J.M.; Zietlow, S.P.; Jenkins, D.H. Use of Unmanned Aerial Vehicles for Medical Product Transport. Air Med. J. 2015, 34, 104-108. [CrossRef] [PubMed]

6. De Leon, R. Zipline Takes Flight in Ghana, Making it the World's Largest Drone-Delivery Network. CNBC. 2019. Available online: https://www.cnbc.com/2019/04/24/with-ghana-expansion-ziplines-medical-dronesnow-reach-22m-people.html (accessed on 25 June 2020).

7. SUAS News. Swoop Aero Triples Malawian Fleet Size to Support COVID-19 Response. 2020. Available online: https://www.suasnews.com/2020/06/swoop-aero-triples-malawian-fleet-size-to-supportcovid-19-response/ (accessed on 25 June 2020).

8. Winkler, M.S.; De La Rosa, S.; Sherman, J.; Blauvelt, C.; Matemba, C.; Maxim, L.; Defawe, O.D.; Gueye, A.; Robertson, J.; McKinney, J.; et al. Bi-directional drones to strengthen healthcare provision: Experiences and lessons from Madagascar, Malawi and Senegal. BMJ Glob. Health 2019, 4, e001541. [CrossRef]

9. GIZ. Drone X-Innovative Transportation Solutions to Improve Access to Medicines and Medical Commodities in Mwanza, Tanzania. 2018. Available online: https://www.updwg.org/wp-content/uploads/ 2019/10/DRONE-X-Innovative-Transportation-Solutions-to-Improve-Access-to-Medicines-and-MedicalCommodities-in-Mwanza-Tanzania.pdf (accessed on 25 June 2020).

10. NESTA. Flying High: Shaping the Future of Drones in UK Cities. 2018. Available online: https://media.nesta. org.uk/documents/Flying-High-executive-summary.pdf (accessed on 25 June 2020).

11. Vosoughi, S.; Roy, D.; Aral, S. The spread of true and false news online. Science 2018, 359, $1146-1151$. [CrossRef] [PubMed]

12. Boucher, P. 'You Wouldn't have Your Granny Using Them': Drawing Boundaries Between Acceptable and Unacceptable Applications of Civil Drones. Sci. Eng. Ethics 2015, 22, 1391-1418. [CrossRef] [PubMed]

13. Thompson, S.; Bracken-Roche, C. Understanding public opinion of UAVs in Canada: A 2014 analysis of survey data and its policy implications. J. Unmanned Veh. Syst. 2015, 3, 156-175. [CrossRef]

14. Clothier, R.; Greer, D.; Greer, D.G.; Mehta, A.M. Risk Perception and the Public Acceptance of Drones. Risk Anal. 2015, 35, 1167-1183. [CrossRef] [PubMed]

15. Zwickle, A.; Farber, H.B.; Hamm, J.A. Comparing public concern and support for drone regulation to the current legal framework. Behav. Sci. Law 2018, 37, 109-124. [CrossRef] [PubMed]

16. Fraser, A. Withcraft and Explosions: Perceptions of Drones in Africa. WeRobotics Blog. 2017. Available online: http://werobotics.org/blog/2017/08/10/witchcraft-and-explosions-perceptions-to-drones-in-africa/ (accessed on 25 June 2020).

17. Eichleay, M.; Mercer, S.; Murashani, J.; Evens, E. Using Unmanned Aerial Vehicles for Development: Perspectives from Citizens and Government Officials in Tanzania. FHI360. 2016. Available online: https://www.ictworks.org/wp-content/uploads/2016/02/UAV-public-perceptions-tanzania.pdf (accessed on 25 June 2020).

18. Raue, M.; D'Ambrosio, L.; Ward, C.; Lee, C.; Jacquillat, C.; Coughlin, J.F. The Influence of Feelings While Driving Regular Cars on the Perception and Acceptance of Self-Driving Cars. Risk Anal. 2019, 39, 358-374. [CrossRef] [PubMed]

19. Bradford, N.; Caffery, L.J.; Smith, A.C. Awareness, experiences and perceptions of telehealth in a rural Queensland community. BMC Health Serv. Res. 2015, 15, 427. [CrossRef] [PubMed]

20. O'Grady, S. How a U.N. Drone Crashed in Congo and Was Promptly Forgotten. Foreign Policy 2015. Available online: https://foreignpolicy.com/2015/09/10/how-a-u-n-drone-crashed-in-congo-and-waspromptly-forgotten/ (accessed on 25 June 2020).

21. VillageReach. Drones for Health. Available online: https://www.villagereach.org/work/drones-for-health/ (accessed on 25 June 2020).

22. Jeyabalan, V.; Nouvet, E.; Meier, P.; Donelle, L. Context-Specific Challenges, Opportunities, and Ethics of Drones for Healthcare Delivery in the Eyes of Program Managers and Field Staff: A Multi-Site Qualitative Study. Drones 2020, 4, 44. [CrossRef]

23. The Department of Civil Aviation, MACRA, VillageReach, GIZ and UNICEF. Malawi Remotely Piloted Aircraft (RPA) Toolkit. 2019. Available online: https://www.updwg.org/wp-content/uploads/2019/12/MalawiRPA-Toolkit-2019_Dec.-Final.pdf (accessed on 25 June 2020). 
24. Mozambique Civil Aviation Authority. Operating Standards: Remote Piloted Aircraft Systems (RPAS). 2018. Available online: https://www.iacm.gov.mz/app/uploads/2018/12/DOS-09-2018-Normas-de-Operacoes-deSistema-de-Aeronave-Pilotada-Remotamente-RPAS.pdf (accessed on 25 June 2020).

25. Democratic Republic of Congo Civil Aviation Authority. Regulating the Use and Operation of Remote Pilot Aircraft in the Democratic Republic of Congo. 2019. Available online: https:/aacrdc.org/WebAAC/DRONES/ DEC026AERONEFTELEPILOTESENRDC.pdf (accessed on 25 June 2020).

26. Dominican Republic Institute of Civil Aviation. Advice on the Use and Operation of Remote Pilot Aircraft Systems (RPAs) or Drones. 2019. Available online: https://www.idac.gob.do/aviso-sobre-el-uso-y-operacionde-aeronaves-pilotadas-a-distancis-rpas-o-drones/ (accessed on 25 June 2020).

27. Tongco, M.D.C. Purposive Sampling as a Tool for Informant Selection. Ethnobot. Res. Appl. 2007, 5, 147. [CrossRef]

28. Topp, L.; Barker, B.; Degenhardt, L. The external validity of results derived from ecstasy users recruited using purposive sampling strategies. Drug Alcohol Depend. 2004, 73, 33-40. [CrossRef] [PubMed]

29. Elo, S.; Kyngäs, H. The qualitative content analysis process. J. Adv. Nurs. 2008, 62, 107-115. [CrossRef] [PubMed]

30. Vaismoradi, M.; Turunen, H.; Bondas, T. Content analysis and thematic analysis: Implications for conducting a qualitative descriptive study. Nurs. Health Sci. 2013, 15, 398-405. [CrossRef] [PubMed]

31. Creative Research Systems. Sample Size Calculator. Available online: https://www.surveysystem.com/sscalc. htm (accessed on 25 June 2020).

(C) 2020 by the authors. Licensee MDPI, Basel, Switzerland. This article is an open access article distributed under the terms and conditions of the Creative Commons Attribution (CC BY) license (http://creativecommons.org/licenses/by/4.0/). 